\title{
EDGAR ALLAN POE EN JAPÓN: IMPACTO EN SU LITERATURA Y EN SU CULTURA
}

\author{
Fernando Cid Lucas \\ Investigador Universidad de Valladolid, Cáceres, España \\ fernandocidlucas@gmail.com
}

\section{RESUMEN / ABSTRACT}

En este artículo se estudiarán la llegada y la recepción crítica de los relatos y la poesía del escritor estadounidense Edgar Allan Poe (1809-1849) en Japón. También se analizará cómo ha influido su obra y él mismo en la cultura popular de Japón, en concreto, en vías de expresión tales como el manga, el animé y los videojuegos.

Palabras clave: Edgar Allan Poe, Periodo Meiji, poesía, recepción, relato.

\section{EDGar ALLAN POE IN JAPAN: impaCt IN ITS Literature AND CULTURE}

In this article we will study the arrival and reception of the stories and poems by the American writer Edgar Allan Poe (1809-1849) in Japan. Furthermore, it will be analyzed how this works and himself have influenced the Japanese's popular culture, specifically in way of expression such as manga, anime and videogames.

KEYWORDs: Edgar Allan Poe, Meiji Period, poetry, reception, tale.

\section{INTRODUCCIÓN}

Que el archipiélago japonés estuvo cerrado, casi a cal y canto, al resto de naciones del mundo durante algo más de dos siglos es muy cierto, viviendo en 
un prolongado feudalismo con características únicas ${ }^{1}$; que tras la vertiginosa Reinstauración Meiji (1866-1869) se trabajó a toda velocidad para recuperar ese "tiempo perdido", también. El ámbito de las letras, como el de la política, la industria o la moda, no iba a ser menos.

Así, si rastreásemos la llegada de la literatura occidental a tierras niponas, descubriremos que, en lo relativo a la de expresión en inglés, el autor primerísimo en llegar al País del Sol Naciente -y acaso el primero de todos en términos universales- fue William Shakespeare (Cid Lucas 6-21), que venía en las valijas de los diplomáticos, embajadores y otros funcionarios de EE.UU. y Reino Unido, no para formar parte de los programas académicos, ni con fines didácticos o como ejemplo de nada para los literatos de allí ${ }^{2}$, sino como divertimento para dichos legados y sus allegados, ya que tenemos constancia de tempranas representaciones de teatro amateur al hilo de reuniones informales entre estos enviados y sus familias, en donde también había música, se charlaba y se comía entre amigos.

Pero en esas tempranas fechas, recién abierto el país asiático a la pujanza de Occidente, llega la obra de un autor tan carismático y único como Edgar Allan Poe (1809-1849), que pronto se traduce y se publica en Japón cosechando inmediatamente una buena acogida entre los lectores. Será su cuento The Black Cat (1843) la primera obra suya que viese la luz en dicho país asiático, en traducción y por entregas - del tres al nueve de noviembre de 1888, en concreto- en un prestigioso diario de la época, el Yomiuri Shimbun. Dicha traducción iba rubricada por Aeba Koson (1855-1922), quien fue un reputado crítico literario, además de traductor y escritor. Hasta ese momento, el relato

1 Véase, para profundizar en este asunto, la magnífica monografía de Duus, Peter. Feudalism in Japan. New York: McGraw-Hill, 1993 (3 edición). Con especial interés el capítulo titulado: "The Emergence of a Centralized", en donde se desgranan las particularidades del periodo de autoaislamiento japonés o sakoku y sus consecuencias en el siguiente periodo histórico.

Aunque no podemos obviar que todo esto lo consiguió el bardo de Stratfordupon-Avon en muy poco tiempo y en idéntica progresión tanto en ámbitos académicos como diletantes. Véanse, por ejemplo, los datos recogidos en el artículo de: Gallimore, Daniel, "Tsubouchi Shōyo and the Beauty of Shakespeare Translation in 1900s Japan". Multicultural Shakespeare: Translation, Appropriation and Performance. Vol. 13 (28), 2016 (pp. 69-85). Trascendiendo lo puramente literario, no hay que olvidar tampoco la notable influencia que tuvo el dramaturgo inglés en uno de los directores de cine más famosos de Japón: Akira Kurosawa, con especial citado de sus filmes Trono de sangre (Kumonosu-jō, de 1957) o Ran (de 1985). 
de Poe tan solo se había vertido al francés ${ }^{3}$ y, tímidamente, al danés y al sueco, siendo este el arribo de nuestro autor al Extremo Oriente.

Koson fue un prolífico hombre de letras, crítico teatral, calígrafo, buen conversador y admirador de la prosa que llegaba desde Occidente, con la que nutrió una buena parte de su biblioteca personal y quien pronto se fijó en los relatos de Poe, que para nada desencajaban con un tipo de relatos que habían sido, desde tiempos muy antiguos, muy del gusto de los japoneses, me refiero a las historias escalofriantes o de terror $\left(\right.$ kaidan $\left.^{4}\right)$, que tan largo recorrido han tenido en Japón (procedentes muchas de ellas desde la vecina China) y cuya pujanza se palpa aún en nuestros días, no solo en la literatura, sino también en multitud de animes o videojuegos. También tradujo Koson el cuento policiaco The Murders in the Rue Morgue (1841), que apareció en el mismo periódico en los días 10, 23, 27 y 30 de diciembre de 1888, y que resultó todo un éxito, logrando el aplauso de un buen número de lectores.

Poco tiempo después, en 1891, ya se enseñaba a Poe en las aulas universitarias de Japón, de manos de esa bisagra humana entre el Oriente y el Occidente que fue el griego Lafcadio Hearn (1850-1904), entonces profesor en la prestigiosa Universidad de Tokyo ${ }^{5}$; fue Hearn quien lo presentó a sus alumnos como un autor preocupado por ahondar en los más profundos recovecos de la mente humana y, a la vez, en el complejo orden del universo, que el de Boston no deja de observar para luego reflexionar sobre él con preocupación. Con todo este conocimiento, dudas y premisas construía Poe un mundo de terror psicológico, perfectamente ubicado en el tiempo y en el espacio, lo que daba visos de certidumbre a todo lo que escribía, por inverosímil que pudiera parecer.

\footnotetext{
Se hace oportuno apuntar ahora que uno de sus primeros traductores en Europa fue el también genial poeta Charles Baudelaire, quien consideraba al escritor de Boston como su "hermano espiritual y de dolor". A lo largo de unos diecisiete años tradujo con devoción, entre otras obras, tres volúmenes de relatos: Histoires extraordinaires (1856), Nouvelles histoires extraordinaires (1857), Histoires grotesques et sérieuses (1865), su novela Les Aventures d' Arthur Gordon Pym (1858) y su ensayo Eureka (1859-1860 y 1863).

$4 \quad$ Si bien, la traducción al español de este término resulta algo complicado, pudiendo proponerse las fórmulas de: cuentos raros, extraños, de intriga o de misterio.

En cuyas aulas estudiaron escritores de la talla de: Sōseki, Tanizaki, Akutawaga, Shiki, Kawabata, Mishima, Ōe o Banana Yoshimoto (nótese que en esta nómina están los dos ganadores del Premio Nobel de Literatura que Japón ha tenido hasta el momento).
} 


\section{EL TERROR EN LA CUENTÍSTICA POPULAR JAPONESA: UN CAMPO ABONADO PARA EDGAR ALLAN POE}

Como decía en el epígrafe anterior, los japoneses pronto aceptaron, casi como a uno de los suyos, a Edgar Allan Poe; tal vez porque lo que contaban sus narraciones no les era en absoluto desconocido y sí les sonaba -y mucho-a algunos de los cuentos recogidos en añosas antologías, tales como Sorori Monogatari, Katakana-bon, Inga Monogatari u Otogiboko; pero también recordaban a autores como el genial Ueda Akinari (1734-1809), escritor que rubricó un buen puñado de títulos en donde los argumentos truculentos se asemejan a los del escritor de Boston, con aparecidos, espíritus y crímenes perversos en las tramas. Precisamente, esa de los crímenes terribles fue una vena explotada por el teatro Kabuki durante el siglo XIX, en obras donde primaba lo cruento del guión y su grandiosa puesta en escena posterior, en donde la entrada de los fantasmas o de los monstruos suponía el momento favorito del público. Una de las obras de este periodo "de plata", como me atrevería a denominarlo, fue la adaptadísima Tokaidō Yotsuya Kaidan (estrenada en 1825), donde un crimen horrendo y el posterior tormento del espíritu de la mujer difunta para con el asesino vertebrará toda la pieza.

Pero también hay cuentos de muertos que vuelven del más allá de forma misteriosa, grotesca y fantasmal, como es el caso del relato del citado Ueda Akinari titulado Nise no en (algo así como El lazo entre las dos vidas), en donde un extraño bonzo, al que se le presuponen virtudes y gran sabiduría, regresa desde el más allá bajo la apariencia de una momia ritual para dar muestras de una completa indolencia hacia el género humano. Por esto, y por muchos ejemplos más sacados de la fértil prosa japonesa, que van desde el inicio del periodo Edo hasta la Reinstauración Meiji, pareciera, a su llegada, que Poe hablara en un idioma muy próximo al que hablaron otros muchos escritores japoneses.

Así, pues, si cotejamos lo hecho por los traductores y los críticos japoneses en comparación con sus vecinos continentales, fue mucho y bueno lo obrado para con el autor de Eureka. Comprobamos que en 1891 se publica una traducción al japonés del que acaso sea su poema más famoso: The Raven (1845); y que ese mismo año vuelve a publicarse otra traducción más de The Black Cat, un relato en donde el felino alcanzaba el mismo protagonismo que multitud de relatos japoneses de terror en donde los nekomatas eran terribles animales con poderes psíquicos y eran capaces de propagar enfermedades mortíferas o enloquecer a los humanos y llevarlos a cometer suicidio. $\mathrm{He}$ 
aquí, por esta similitud entre los argumentos, uno de los motivos del éxito de acogida de este breve relato en Japón ${ }^{6}$.

Y en menos de cuatro años, en 1895, verá la luz la traducción de otro de los principales poemas de Poe, The Bells (obra póstuma, de 1849), que influyó en bastantes poetas nipones de la época, que buscaban una forma nueva de expresarse, alejada del pentasílabo y el heptasílabo, raíz y ramas maestras del árbol de las estrofas imperantes hasta ese momento en la lírica nipona: waka, renga o haiku (Rodríguez-Izquierdo y Gavala 10-110). Poe y otros poetas, como Walt Whitman (1819-1892) u Oscar Wilde (1854-1900), llevaban a Japón una forma nueva de entender la poesía: libre, comunicativa en cada una de sus palabras, aparentemente anárquica... pero, además, en la poesía de Poe-lo mismo que sucedía con su prosa- los japoneses encontraron, nuevamente, un discurso conocido, asequible para hacer ellos a manera de los occidentales, pero sin perder su tan respetada idiosincrasia asiática.

Poco conocido aún en Occidente, pero crítico reputado en Japón, cuyas obras han tenido eco en tiempos posteriores, es Shimamura Hōgetsu (18711918), quien en 1895 publicó un curioso ensayo dedicado a la novela de detectives $^{7}$, sin duda motivado por la pujanza que los relatos de Poe estaban teniendo entre los lectores de la época y por sus propios gustos literarios. En 1896 se traduce el relato The Cask of Amontillado (1846); y antes de que termine el siglo XIX, en 1899, se hará lo propio con Berenice (1835) y The Premature Burial (1844), publicado en Japón en 1900. Todos muy del gusto japonés, todos saludados con gusto por la crítica y todos fácilmente incluibles en la antología de relatos sobrenaturales y de miedo que es Otogi Boko, del monje budista Asai Ryōi (h. 1612-1691), que vio la luz en la "diabólica" fecha de 1666.

Lo mismo que los autores que hasta ahora hemos citado, que podrían circunscribirse en el círculo de quienes apostaron desde el primer momento por una renovación de las letras en Japón, oponiéndose valientemente al

6 Por ejemplo, el país vecino, China, tuvo que esperar hasta 1909 y al genial Lu Xu (1881-1936), uno de los escritores más influyentes de la literatura de dicho país durante todo el siglo XX, para ver traducido este cuento al idioma chino. Pero esto se produjo, precisamente, cuando el autor se encontraba estudiando medicina en Japón, en la universidad de Sendai, en concreto. Como hemos visto, en esos años Poe ya no era un desconocido en el País del Sol Naciente.

Género que no existía en la prosa del País del Sol Naciente y que fue una aportación más de los occidentales a la literatura japonesa. 
círculo conservador, y que fueron pujantes en su momento, pero que, a día de hoy están en un franco segundo plano, escritores tan influyentes y que siguen estando en el canon de la literatura japonesa, como es el caso de Sōseki, Tanizaki o Akutagawa, también se fijaron en el autor estadounidense. En relación con esto, sorprende la cantidad de seguidores y de imitadores que tuvo Poe en Japón tras una primera etapa de "aterrizaje", y la buena acogida que tuvieron sus relatos y poemas, que sirvieron como modelo para muchos autores en el País del Sol Naciente.

El caso de Natsume Sōseki (1867-1916), becario de la Universidad de Tokyo en Londres durante los años 1901-1903, nos resultará curioso, ya que sus ideas preceptivas, en cuanto a poesía ${ }^{8}$ y prosa se refiere, marchan por caminos opuestos comparándolas con las de Poe. Se ha tendido a olvidar que Sōseki, hombre de una honda finura intelectual y de unos sólidos conocimientos sobre la literatura china, japonesa y también de expresión inglesa, se fijó pronto en la obra de Poe (lo mismo que en la lánguida belleza que desprendían las prosas de Wilde y en el rememorar la belleza clásica del pasado en los poemas de Keats), dedicándole varios escritos. En el ensayo titulado Poe no sozo (La imaginación de Poe), acaso el más conocido, Sōseki alaba lo que hay de pensamiento científico en los relatos de Poe, el recurrir a la ciencia para transformarla en pura literatura, compartiendo lugar ésta con las escenas de misterio y con el tono lúgubre del que hacen gala las atmósferas del autor de Boston.

Algo posterior a Sōseki fue Junichirō Tanizaki (1886-1965), en quien también se reconocen las influencias de Poe (lo mismo que las de Oscar Wilde), esta vez en el uso oscuro del elemento grotesco en relatos suyos como Kagi (La llave) y, sobre todo, en un cuento anterior a éste, Shisei (El tatuador), que uno de los críticos más agudos del momento -y excelente escritor de cuentos también-, Akutagawa, alabó sin tapujos, diciendo de

\footnotetext{
Aunque en Occidente Sōseki sea conocido, sustancialmente, por su labor como novelista (Satori o impedimenta han publicado desde el japonés sus obras más representativas), fue un consumado autor de poemas al estilo chino y de haikus, faceta que estamos comenzando a descubrir en nuestro país. Sobre su labor como poeta, en español podemos leer: Cid Lucas, Fernando (ed.). Para otras mil generaciones más... Antología poética japonesa desde el Kojiki a nuestros días. Madrid: Amargord, 2013; y Sōseki, Natsume. Sueño de la libélula. Gijón: Satori, 2013. Este último título en traducción, selección y comentarios del profesor Fernando Rodríguez-Izquierdo y Gavala, quien también realiza un semblante del autor en el prólogo del libro.
} 
él que estaba lleno de un hondo espíritu poético en conjunción con el puro horror, y en donde se mezcla el dolor de las agujas que van horadando la piel con la belleza final del tatuaje, presentando el sufrimiento como condición sine qua non para obtener la hermosura. Sin embargo, Shisei fue cuestionado por la crítica más mojigata de su país, como otras tantas obras suyas más, por considerarse indecorosas. Sí hay en los relatos de Tanizaki una belleza rara, delicada y decadente, lo que es otra llamada a la estética de Poe; otro ejemplo más sería la novela Yoshino Kuzu (La enredadera de Yoshino), de 1930, de ambiente etéreo y mórbido.

Contemporáneo de Tanizaki fue el poeta Hagiwara Sakutarō (1886-1942), una de las figuras líricas más importantes de su generación, quien sigue una línea nueva en la composición de sus poemas, alejada de las formas clásicas ${ }^{9}$. A él debemos una libre adaptación del poema The Raven, que le impactó -además de por su contenido- por la forma en la que se expresaba su autor, buscando la plasticidad de cada uno de los versos. Así se refiere a él en uno de sus ensayos: "The expressive effect of Poe unrhymed (sic) poem "The Raven" result from the repeated echoes of the gloomy, eerie sounds of such words as nevermore and Leonore, which sound like the wind blowing from some lonely, distant graveyard" (Keene 268).

Esta admiración de Hagiwara por el uso del sonido en los poemas de Poe, por emplear con maestría la onomatopeya, el encabalgamiento, etc., le hará imitarlo en sus propios poemas, como el titulado Neko (Gato), una "respuesta japonesa" a The Raven, en donde encontraremos versos tan rítmicos como: Makkuroke no neko ga nihiki...(Hagiwara 68) (Algo como: "Dos gatos, negros como el azabache..."), un recurso que, por otro lado, también habían explotado ya algunos maestros del waka y del haiku.

Y un autor de aires tan japoneses como el aludido Ryūnosuke Akutagawa (1892-1927), que ha dado nombre a un codiciado premio literario en su país de origen, también se fijó en la forma y el estilo de Poe. En 1913 comenzó sus estudios de literatura inglesa en la acreditada Universidad de Tokyo, junto a otros escritores que también pudieron conocer la obra de Poe, como Kikuchi, Yamamoto o Tsuchiya. Pero también conoció la obra de Poe mediante las

$9 \quad$ Tras la citada Restauración Meiji (1866-1869), será uno de los intelectuales que se afilien a la doctrina cristiana, fe a la que pertenecían otros escritores, como el gran novelista Shūsaku Endō (1923-1996). 
conversaciones con su amigo Sōseki, quien fue para él una notable influencia ${ }^{10}$. En su ensayo titulado Tampensakka toshiteno Poe (Poe como escritor de relatos $\left.\operatorname{cortos}^{11}\right)$, de 1922, Akutagawa viene a desmenuzar la poética y la manera de narrar del autor norteamericano, y pienso que él llegó a comprender muy bien las técnicas narrativas del autor de The Raven, que sirvieron luego para terminar de conformar su propio estilo, tal y como han señalado algunos autores contemporáneos (Ciapparoni La Rocca (ed.) 20-63). Por ejemplo, la angustia mental, la fatiga o la locura que exhiben protagonistas de uno y otro autor están muy próximas en sus respectivas definiciones.

Y este breve trabajo no estaría completo sin ni siquiera citar a la carrera a Edogawa Ranpō (1894-1965), pseudónimo literario de Tarō Hirai ${ }^{12}$, el denominado "Poe japonés", que dedicó gran parte de su vida a imitar el estilo del original. Mucho tiempo pasó leyendo a dicho autor y llegó a crear la "Asociación Japonesa de Escritores de Misterio", que congregó en torno a ella a otros buenos lectores japoneses de Edgar Allan Poe, y fue ésta la entidad que instaurase en el país asiático el premio anual a la mejor novela de misterio. Es autor de un ensayo, Dikens vs. Poe (de 1951), en el que compara a ambos autores.

Yumeno Kyūsaku (1889-1936) nació algunos años antes que Edogawa Ranpō y está considerado también como otro Poe a la japonesa o, al menos, como un hermano nipón de dicho autor estadounidense. Menos conocido en Occidente que Edogawa Ranpō, ya que sus novelas no se han traducido aún -salvo un par de títulos al inglés y al francés, con tímida acogida por parte de los lectores-, las historias de Yumeno contienen grandes dosis de violencia e, incluso, de lo que en el lenguaje cinematográfico denominaríamos de "casquería barata", guardando un lugar prominente para crímenes y escenas

10 La relación de Akutagawa con la literatura de expresión inglesa fue notable. Recordemos que en 1924 se encarga de la publicación de la monografía More Modern Ghost Stories para la colección The Modern Series of English Literature, que sirvió en Japón para abrir las puertas a las letras de Occidente y donde aparecían autores como Bierce, Blackwood o Wood.

11 Es bien sabido por la crítica que esta fue la forma que siempre interesó a Akutagawa, aunque intentara la novela y también la poesía. En Poe encontró a un autor occidental quien, como él, había elegido el relato corto como forma predilecta para expresarse, logrando que nada faltara en él, a pesar de la brevedad de algunos de sus cuentos.

12 En España, la editorial gijonesa Satori ha comenzado a publicar varias colecciones de relatos de este autor, traducidos todos desde el japonés original, prologados y anotados por especialistas. 
sangrientas. En su obra magna, Dogra Magra, de 1935, se han querido ver algunas reminiscencias de Edgar Allan Poe; en ella, su protagonista, Ichirō, despierta un día en un psiquiátrico sufriendo una amnesia total. Más tarde descubrirá que ha intentado asesinar a su prometida. La angustia y el desconocimiento de sí mismo, intentando discernir verdad y alucinaciones, avanzarán desde el principio hasta el final de la novela.

Y, desde luego, figura importantísima para la difusión de Poe en Japón, tanto para los lectores como para otros escritores, fue Midori Ozaki (18961971), una mujer adelantada a su tiempo, libre, abanderada del feminismo japonés ya en la década de los años 20 del pasado siglo y gran conocedora de la literatura japonesa ${ }^{13}$, pero también de la extranjera. Seguidora de las estéticas europeas del Modernismo y también del Expresionismo, a ella debemos la traducción al japonés del relato Morella (1835), el cuento de la culta y misteriosa mujer que consigue la inmortalidad a través de su profundización en lecturas prohibidas y artes oscuras. Un relato que impactó a Ozaki, mujer progresista y desinhibida que se desmarcaba del arquetipo de mujer sumisa y servicial -propia del Japón de épocas pasadas-, y ávida lectora de historias de terror desde su juventud. Desgraciadamente, la carrera literaria de Ozaki se vio truncada por su adicción a los barbitúricos y por una inestabilidad nerviosa que arrastraba desde su juventud. En 1932, ya muy deteriorada, y de la mano de su hermano, deja la agitada capital del país para retirarse a una vida más tranquila en su pequeña ciudad natal en la prefectura de Tottori, donde falleció a los 74 años.

Terminaré esta somera enumeración de nombres propios con un autor que indagó tanto en la literatura patria como en la extranjera, y quien supo aprovecharse y nutrirse de lo mejor de cada una de ellas para acrisolar una muy personal preceptiva: Yukio Mishima (1925-1970); escritor que sentenció sobre el autor de Boston que: "Poe displayed his taste for intelectual nonsense and that the intellect that has hidden itself completely in nonsensical tall tales becomes paradoxically most beautiful and artistic" (cit. en Mizuta 145).

A la luz de todo lo dicho, podemos concluir que la progresión de Edgar Allan Poe en el País del Sol Naciente se ha mantenido firme y en dirección ascendente hasta hoy. Así, de 2005 a 2018 se han publicado decenas de artículos y capítulos de libros (redactados en japonés y en inglés) que han

13 Ligada a otras dos grandes autoras niponas de esa misma época: Fumiko Hayashi y Taiko Hirabayashi. 
merecido el respeto de la comunidad mundial de investigadores sobre $\mathrm{Poe}^{14}$. Trabajo encomiable ha realizado la "Poe Society of Japan", ya que tiene como cometido la organización anual de un congreso internacional donde se den cita especialistas llegados desde cualquier punto del planeta para compartir sus aportaciones y la publicación de un boletín dedicado a la vida y obra del escritor norteamericano. Sin ir más lejos, en 2007, celebrando los 200 años del nacimiento del autor, dicha asociación editó el libro The Japanese Face of Edgar Allan Poe, donde se recogen numerosos estudios centrados en el escritor que se han reseñado ya en multitud de ocasiones.

Moviéndonos hasta otro lado de la sociedad japonesa, podemos afirmar también que Poe ha sido -y sigue siendo- un autor querido por los japoneses, quienes han adaptado sus obras a la cultura urbana, tocando esta transformación a formas tan modernas de la cultura de masas como pueden ser el manga, el animé , el cosplay o los videojuegos, lo que siempre es enriquecedor, por lo que tienen dichas formas de puente tendido hacia la literatura para las nuevas generaciones. Así, muchos de estos jóvenes reconocen que su primer encuentro con el escritor estadounidense no se obró con la lectura de sus obras, sino por la adaptación para el manga de éstas, o como personaje él mismo de cómics o series de animación.

\section{EDGAR ALLAN POE Y LA CULTURA DE MASAS DE JAPÓN}

De manera expositiva, por los rigores que la extensión máxima marca para el texto, examinaremos la pujanza de Edgar Allan Poe en la inabarcable cultura de masas japonesa. Comenzando por su cine, Julio Ángel Olivares Merino, de la Universidad de Jaén, ha detectado las influencias de las inquietantes escenas interiores y las frías y estáticas descripciones exteriores de varios relatos de Poe en la cinta más famosa del director Masaki Kobayashi (1916-1996), Kwaidan (El más allá), de 1964, un muy plástico homenaje a las historias de terror y a los cuentos de fantasmas y aparecidos del viejo Japón que fascinó al ya aludido Hearn. Olivares ha señalado de Kwaidan su "vaguedad mortecina y la poética consunción o evanescencias". Atmósferas

14 Véanse para esto los datos y estadísticas recogidas en: http://www.poejapan.org/ (última consulta: 25/11/2018). 
aplicables a los relatos del mejor Poe ${ }^{15}$. Y va más allá (valga la redundancia), al asemejar a la protagonista del episodio titulado "El cabello negro" de la cinta de Kobayashi con las siempre enigmáticas mujeres salidas de la pluma del escritor norteamericano (Olivares Merino 16).

Desplazándonos hasta una forma más moderna como es el cómic, también la figura de Edgar Allan Poe ha servido para argumentos de mangas; tal es el caso de Pō no Ichizoku (La familia Poe), de la excelente mangaka Mōto Hagio (1949- $)^{16}$, que se editó entre 1972 y 1976. Sus protagonistas son Edgar Portsnell, nacido en 1740 e hijo ilegítimo de un rancio aristócrata, que se convierte en vampiro a los catorce años, y su hermana Marybell, vampira desde los trece. Una adelantada historia de vampiros lánguidos y románticos, nacida mucho antes que la ultramediática Crepúsculo. Dicho título inspiró posteriormente su adaptación para el cine de animación y hasta un serial radiofónico que seguían jóvenes y no tan jóvenes en el País del Sol Naciente.

Película de animación, dramática, surrealista, de horror y hasta sadomasoquista es Shōjo tsubaki: Chika gentō gekiga ${ }^{17}$ (título que se ha traducido al español como: Midori: la niña de las camelias), de Hiroshi Harada, que se inscribe en la estética del cine eroguro (sangre y erotismo). La cinta comienza con imágenes terroríficas de los viejos fantasmas y espíritus japoneses (los yōkai), para dar paso a la historia de una desdichada niña, Midori, huérfana a muy temprana edad, como el joven Frederick del relato Metzengerstein (1832). Personajes devorados por ratas, callejones oscuros, hombres mutilados que parecen momias, un circo grotesco donde se exhiben quimeras y encuentra refugio cualquier parafilia... Un mundo bizarro solo posible en mentes como la de Harada o la de Poe.

Sin estar rubricada por japoneses, pero imitando en todo la estética japonesa, está la versión animada de The Raven, hecha por el equipo "Blue Bliss", que ha conseguido miles de reproducciones en youtube. Como anécdota, diremos que el protagonista de la adaptación del poema de Poe tiene las facciones del gran Toshirō Mifune (1920-1997), actor fetiche del director Akira Kurosawa (1910-1998).

15 Es interesante reseñar que Kobayashi adaptó para el cine cuatro historias que previamente habían sido compiladas por Lafcadio Hearn (gran admirador de Poe, como hemos señalado) desde la oralidad nipona.

16 Autora también del famosísimo manga titulado Zankokuna Kami ga Shihai Suru, que le valió el codiciado premio "Osamu Tezuka" en el año 1997.

17 Estrenada en 1992. 
Pero Edgar Allan Poe también está en la calle en el Japón de 2019, en la indumentaria de los jóvenes cosplayers que inundan los barrios más populosos de su capital, como Shinjuku o Harajuku, vestidos éstos como personajes sacados de sus relatos o como el mismo escritor, recordándonos que aún es un autor querido por las nuevas generaciones, quienes han hecho de su atormentada apariencia física y de las de sus personajes su manera de vestir y de transitar por el moderno, y a la par conservador, País del Sol Naciente.

\section{BIBLIOGRAFÍA}

Aguilar, Daniel. Japón sobrenatural. Gijón: Satori, 2013.

Akinari, Ueda. Cuentos de lluvia de primavera. Gijón: Satori, 2013.

Baudelaire, Charles. Edgar Allan Poe. Madrid: Visor, 1989.

Caeiro, Luis. Cuentos y tradiciones japoneses. I. El mundo sobrenatural. Madrid: Hiperión, 1993.

Ciapparoni La Rocca, Teresa (Ed.). Akutagawa Ryunosuke. Studi da Oriente ad Occidente. Roma: Nuova Cultura, 2011.

Cid Lucas, Fernando. William Shakespeare en Japón: su recepción y proyección en los géneros teatrales nipones. Un esbozo de cronología razonada. Cáceres: A priori Comunicaciones, 2008.

Hagiwara, Sakutarō. Hagiwara Sakutarō Zenshū (I). Tokyo: Shinchōsha, 1959.

Jacobowitz, Seth. Introduction to The Edogawa Rampo Reader. Fukuoka: Kurodahan Press, 2008.

Kato, Shuichi. A history of Japanese Literature. Tokyo, New York y London: Kodansha International, 2002.

Keene, Donald. Dawn to the West. New York: Columbia University Press, 1999.

Long, Margherita. This Perversion Called Love: Reading Tanizaki, Feminist Theory, and Freud. Palo Alto: Stanford University Press, 2009.

Lovecraft, Howard Phillips. El horror en la literatura. Madrid: Alianza Editorial, 2002.

Minato, Keiji. "Poe and the Position of the Poet in Contemporary Japan". The Edgar Allan Poe Review, vol. 5, nº 1 (2004): 29-46.

Mizuta, Noriko. "Tanizaki and Poe: The Grotesque and the Quest for Supernal Beauty". Comparative Literature, vol. 29, $\mathrm{n}^{\circ} 3$ (1977): 221-240.

"Poe in Japan". Poe Abroad: Influence, Reputation, Affinities (Lois V. ed). Iowa City: University of Iowa Press, 1999.

Olivares Merino, Julio Ángel. "Narratarios del Silencio Tematizado: "El Más Allá" (Kwaidan), de Masaki Kobayashi”. Revista Especulo. Marzo-Junio 2002. https://webs.ucm.es/info/ especulo/numero20/masalla.html

Palacio, Jesús (ed.). Eroguro: Horror y erotismo en la cultura popular japonesa. Gijón: Satori, 2018. 
Rampō, Edogawa. Los casos del detective Kogoro Akechi (traducción de Rumi Sato y con un epílogo de Daniel Aguilar). Gijón: Satori, 2017.

Risco, Antón, Ignacio Soldevilla y Arcadio López-Casanova (Eds.). El relato fantástico. Historia y Sistema. Salamanca: Ediciones Colegio de España, 1998.

Rodríguez-Izquierdo y Fernando Gavala. El haiku japonés. Madrid: Hiperión, 2001.

Rubio, Carlos. Claves y textos de la literatura japonesa. Madrid: Cátedra, 2007. 